\title{
Effect of Proton Pump Inhibitors, Vitamin E and their co- administration on heart function and Oxidative Changes in Isoprenaline Induced Myocardial Infarction in Adult Male Albino Rats
}

\author{
Abeer A. Shoman ${ }^{\mathrm{a}}$, Ahmed D. Badwy ${ }^{b}$, Mohamed S. Elhammady ${ }^{\mathrm{a}}$, Yara S. Eldesok ${ }^{\mathrm{b}}$
}

a

Department of physiology,

Benha faculty of medicine, Benha University, Egypt, ${ }^{\mathrm{b}}$ department of physiology $6^{\text {th }}$ October Univerisity, Egypt.

Correspondence to: Abeer A. Shoman, Department of physiology, Benha faculty of medicine, Benha University, Egypt

Email:

shoman_abeer@yahoo.com

Received: 4 December 2019

Accepted: 30 December 2019

\section{Abstract:}

Background: Myocardial infarction (MI) continues to be associated with high morbidity and mortality worldwide. Proton Pump inhibitors (PPIs) exhibit cardioprotective effects by several mechanisms. Vitamin E possesses antioxidant properties. Aim: The present study has been designed to evaluate the combined cardioprotective effect of PPIs and vitamin E on biochemical and histopathological alteration in isoprenaline (ISO) induced myocardial infarction in rats. Methods: 30 adult Wistar albino male rats divided into 5 groups as follow: Group I: Control fed a standard diet. Group II: rats were undergoing MI by ISO. Group III: Rats were pretreated pantoprazole $(1.3 \mathrm{mg} / \mathrm{kg}$, i.o) daily for 3 weeks. Group IV: Rats were pretreated with vitamin E (100 IU/kg i.o) daily for 3 weeks. Group V: Rats were given both pantoprazole (1.3 $\mathrm{mg} / \mathrm{kg}$, i.o) and vitamin E (100 IU/kg bw, i.p) daily. On $22^{\text {th }}$ and $23^{\text {th }}$ day, rats in groups (II-V) were injection i.p with ISO $(100 \mathrm{mg} / \mathrm{kg} \mathrm{bw}$ for successive two days). Results: ISO induced infarction in rats resulted in a significant elevation in ST segment height, T - wave voltage, Heart rate (HR), serum lactate dehydrogenase (LDH), malondialdehyde (MDA) and nitric oxide metabolites (NO), whereas it caused a significant $(\mathrm{P}<0.05)$ decrease in systolic blood pressure $(\mathrm{SBP})$ and serum superoxide dismutase (SOD) when compared with the control group. Moreover, interventions with PPIs supplementation and/or vitamin E significantly reversed the aforementioned parameters with better impact of their combination. Conclusion: PPIs combined with vitamin E exert potential protective effect against MI through lowering calcium overload and enhancement of antioxidant activity. 
Keywords: ISO and oxidative stress, MI, PPIs, vitamin E.

Abbreviation: MI; myocardial infarction, PPIs; proton pump inhibitors, ISO; isoprenaline, HR; heart rate, SBP; systolic blood pressure, LDH; lactate dehydrogenase, MDA; malondialdehyde, SOD; superoxide dismutase and NO; nitric oxide metabolites.

\section{Introduction}

Myocardial infarction (MI) is one of the most cardiovascular disorders caused by sudden blockage of blood supply to myocyte (1). Experimentally, MI can be induced by injecting animals with isoproterenol (ISO) that act as sympathomimetic agonist (2).

Isoprenaline (ISO), a synthetic catecholamine, is known to have a toxic effect on the heart. The mechanisms that ISO -induced cardiac damage is through generation of reactive oxygen species and depletion of antioxidant capacity (3)

Proton pump inhibitors (PPIs) are a class of drugs that share a benzimidazole compound as a common core structure. They know to possess other biological activities apart from suppression of proton pumps (4). Both animal and human tissue studies showed that $\mathrm{H}+\mathrm{K}+-$ ATPase expressed in myocardium and PPIs have electrophysiologic effects (5)

Although PPIs have been developed with the particular goal of therapy which is treating gastric hyperacidity, in recent years PPIs were 170 associated with benefits in the treatment of angina pectoris and myocardial ischemia. (6)

Vitamin $\mathrm{E}$ is a fat-soluble vitamin and potent antioxidant. It is believed to be important in protecting cells from oxidative stress, regulating immune function, maintaining endothelial cell integrity and balancing normal coagulation (7).

During acute MI, superoxide radicals modulate the activity of superoxide dismutase, resulting in reduced activity of this enzyme and accumulation of superoxide radicals, with consequent damage to the myocardium (8).

Subsequently, this study was designed to investigate the potential protective effect of PPIs in combination induced by ISO in rats.

\section{Materials and Methods:}

\section{Animals:}

This was a prospective study which started from April 2018 until August 2018. The study was approved by the Institutional Review Board and reference number was BU -IRB\#: 4159. It was conducted on thirty adult male albino rat weighting between 170 and 200 gm for 3 weeks (21 day). The animals were randomly divided into five groups. Each group was consisted of six rats. Each three rats were housed in a separate cage. They 
were obtained from the Experimental Animal Unit of Moshtohor faculty of agriculture. The animals were acclimatized to the laboratory conditions for 10 days prior to the initiation of the experiment. They had free access to water and diet. Well trained person was handling the rats. By the end of the experiment and after collection of the samples, we got rid of the animals in the incinerator of Benha University hospital.

\section{Drugs:}

1. Pantoprazole: Was purchased from (Sigmatec ,6 October city, Egypt). It was available in the form of pantoprazole sodium hydrate (white powder 10MG). We dissolved it in $1 \mathrm{~mL}$ phosphate buffered saline (PBS).

2. PBS: was purchased from (National Organization for drug and Control Research, Egypt)

3. Vitamin E: was purchased from (Sigma Aldrich Co.) provided as yellow liquid (DL-Alpha Tocopherol Acetate). We dissolved it in olive oil.

4. Isoprenaline: Was purchased from (Sigma
Aldrich Co.)
(DL-Isoproterenol hydrochloride) provided as white powder. We dissolved it in saline before use.
5. Urethane: provided as white powder (Sigma, U.S.A.). We dissolved it in saline before use.

\section{Experimental group:}

This study was carried out on 5 groups of adult male albino rats $(\mathrm{n}=6)$ as follow: -

First group (group I) was the control group which was maintained on standard diet and water for 3 weeks. Second group (group II) was injected with ISO subcutaneously by the end of 3 weeks in dose of $100 \mathrm{mg} / \mathrm{kg}$ for two successive days. Third group (group III) was pantoprazole pretreated group $1.3 \mathrm{mg} / \mathrm{kg}$ dissolved in $1 \mathrm{~mL}$ PBS once daily by gastric tube for 3 weeks then a myocardial infarction was induced with injection of ISO which was performed during two consecutive days and 24-hour interval between them (on 22th and 23th day). Fourth group (group IV) was pretreated with vitamin E $100 \mathrm{mg} / \mathrm{kg}$ once daily for 3 weeks then a myocardial infarction was induced by injection of ISO, performed during two consecutive days and 24-hour interval between them (on 22th and 23th day). Fifth group (group V) received both pantoprazole along with vitamin $\mathrm{E}$ in a dose of $1.3 \mathrm{mg} / \mathrm{kg} / \mathrm{day}$ and $100 \mathrm{mg} / \mathrm{kg} / \mathrm{day}$ respectively for 3 weeks then a myocardial infarction was induced by injection of ISO, performed during two consecutive days and 
24-hour interval between them (on 22th and 23th day)

\section{Experimental procedure:}

\section{A. Induction of myocardial infarction}

MI was induced in rats by subcutaneous injection of $100 \mathrm{mg} / \mathrm{kg}$ isoprenaline hydrochloride dissolved in saline once daily for two successive days. (9).

\section{B. Hemodynamic parameters measurements}

By the end of experiment SBP and HR were recorded on a computer with data analysis software (Power Lab data acquisition system; AD Instruments, Bella Vista, Australia).

\section{ECG Recording}

The animals were anesthetized with urethane at a dose $1.25 \mathrm{~g} / \mathrm{kg}$, dissolved in saline, half the dose was injected intraperitoneally for a rapid action and the other half was injected subcutaneously for a slow sustained action (10). Then the ECG was recorded and analyzed using data analysis software (Power

Lab data acquisition system; AD Instruments, Bella Vista, Australia). The lead II ECG was recorded from needle electrodes inserted subcutaneously into the right forelimb and into each hindlimb.

\section{Biochemical Estimation}

Blood samples were collected from the right ventricle before removal of the heart from the chest. The blood was left until clotting. Serum was separated by centrifugation at 3000 revolution per minute (rpm) for $15 \mathrm{~min}$. Cardiac marker enzymes such as LDH was detected using LDH kits obtained from Biosystem Egypt (Spain). In addition, Nitric oxide (NO) production was estimated from the amounts of nitrite (NO2-) and nitrate (NO3-) in deproteinized serum samples assayed with total NO assay kit (purchased from Biodiagnostic, Egypt). Measuring the $\mathrm{NOx}-$ levels has been confirmed as a reliable method of determining the synthesizing capacity of NO synthase (NOS) in the heart (11).

MDA a lipid peroxidation product was measured as a marker for oxidative stress in serum (12), it was assessed by MDA kits which purchased from Cambridge, UK, were used to assess serum MDA level by enzymatic colorimetric assay. SOD kits (Cat. No. KT-745), purchased from KAMIYA BIOMEDICAL COMPANY (Tukwila, USA) were used to assess the activity of SOD (13).

\section{E. Histological Examination}

The animals were sacrificed by cervical dislocation, hearts were rapidly dissected out and washed immediately with saline and fixed in $10 \%$ buffered formalin. The heart tissues were embedded in paraffin, sectioned at $5 \mu \mathrm{m}$, 
and stained with hematoxylin and eosin $(\mathrm{H} \&$ E) (Drury and Wallington, 1980). The sections were examined under the light microscope and photomicrographs were taken.

\section{Statistical Analysis}

The collected data were summarized in terms of mean \pm Standard Deviation (SD). Comparisons between the different study groups were carried out using the one-way analysis of variance (ANOVA; $F$ value) followed by post hoc tests using the LSD method using the Statistical Package for Social Science (SPSS) program, version 19 (Chicago IL USA, 2000). p-value < 0.05 was considered statistically significant.

\section{Result:}

\section{Effect of PPIs, vitamin E on ECG patterns} in ISO-induced myocardial infarction in rats

Subcutaneous injection of isoprenaline for two successive days induced MI resulted in a significant increase $(\mathrm{p}<0.05)$ in $\mathrm{T}$ wave voltage, ST segment height with a decrease in $\mathrm{R}$ wave amplitude as compared to the control group. Pretreatment with PPIs, vitamin E or their combination for 3 weeks resulted in a significant reduction $(\mathrm{p}<0.05)$ in the $S T$ segment elevation and hyperacute $\mathrm{T}$ - wave with an increase in $\mathrm{R}$ wave amplitude as compared to the isoprenaline injected group as shown in table 1 and fig.1(A,B,C,D,E).

Effect of PPIs, vitamin $\mathbf{E}$ on hemodynamic parameters in ISO induced myocardial infarction in rats

Isoprenaline significant decreased $(\mathrm{p}<0.05)$ SBP with significant increase in $H R$. Pretreatment with PPIs, vitamin E or their combination for 3 weeks resulted in a significant increase $(\mathrm{p}<0.05)$ in SBP with reduction in $\mathrm{HR}$ as compared to the isoprenaline injected group as shown in table 2.

Effect of PPIs, vitamin $\mathrm{E}$ on biochemical changes in ISO-induced myocardial infarction in rats

There was a significant elevation $(\mathrm{p}<0.05)$ in serum LDH along with concomitant increase in serum MDA and NO in Group II, (ISO myocardial infarct rats), as compared to Group I (non-infarct control rats) and all other pretreated Groups. Pretreatment with pantoprazole (Group III), vitamin E (Group IV) and pantoprazole + vitamin $\mathrm{E}$ in combination (Group V) for 3 weeks before ISO administration significantly $(\mathrm{P}<0.05)$ reduced the levels of serum $\mathrm{LDH}, \mathrm{NO}$ and the activity of MDA with the lowest values to near normal range in Group $\mathrm{V}$ when compared to rats injected with ISO alone (Group II) as shown in table 3. 
The mean serum levels of SOD in Group II (ISO myocardial infarct rats) was significantly lower than those observed in control and all other pretreated groups $(\mathrm{p}<0.05)$. Pretreatment with pantoprazole (Group III), vitamin E (Group IV) or pantoprazole+ vitamin $\mathrm{E}$ in combination (Group V) for 3 weeks and challenged with ISO resulted in a significant $(\mathrm{P}<0.05)$ increase in the activity of SOD with the highest values of SOD were noticed in Group $\mathrm{V}$ followed by Group IV when compared to rats injected with ISO alone (Group II) as shown in table 3

\section{Histopathological changes}

Histological examination of the cardiac tissue in the control group, showed that, myocardial fibers were arranged regularly with clear striations, without any damage or necrosis in the tissue (fig.2A). architecture near normal with minimal hemorrhage in between these cardiac muscle fibers (fig.2E).
ISO infarcted rats, the cardiac muscle fibers were interrupted and separated from each other with wide intercellular spaces with severe cellular infiltration and severe hemorrhage in between the cardiac muscle fibers, dilated and congested blood vessels were seen (fig.2B). Pantoprazole pre-treated rats then challenged with ISO, showed near normal myocardial architecture and slight hemorrhage in between the cardiac muscle fibers (fig.2C). Cellular changes in vitamin $\mathrm{E}$ pre-treated group then injected with ISO were less as compared to group II. (fig.2D). Combination of pantoprazole along with vitamin $\mathrm{E}$ pretreated rats then infarcted with ISO showed that, the myocardium recovered its histological architecture near normal with minimal hemorrhage in between these cardiac muscle fibers (fig.2E).

Table (1): Effect of PPIs, vitamin E, and their combination on ECG patterns on ISO induced MI in rats in different experimental groups.

\begin{tabular}{llllll}
\hline & Group I & Group II & Group III & Group IV & Group V \\
\hline ST Segment & $0.03 \pm 0.01$ & $0.28 \pm 0.02^{\mathrm{a}}$ & $0.13 \pm 0.01^{\mathrm{a}, \mathrm{b}}$ & $0.13 \pm 0.01^{\mathrm{a}, \mathrm{b}}$ & $0.1 \pm 0.01^{\mathrm{a}, \mathrm{b}, \mathrm{c}, \mathrm{d}}$ \\
height (mv) & & & & & \\
T-wave voltage & $0.19 \pm 0.04$ & $0.88 \pm 0.09^{\mathrm{a}}$ & $0.36 \pm 0.05^{\mathrm{a}, \mathrm{b}}$ & $0.34 \pm 0.03^{\mathrm{a}, \mathrm{b}}$ & $0.23 \pm 0.05^{\mathrm{b}, \mathrm{c}, \mathrm{d}}$ \\
$(\mathbf{m v})$ & & & & & \\
\hline
\end{tabular}

Data are represented as mean $\pm \mathrm{SD} . \mathrm{P}<0.05$ is considered statistically significant

${ }^{\mathrm{a}} \mathrm{P}<0.05$ vs. control group; ${ }^{\mathrm{b}} \mathrm{P}<0.05$ vs. group II; ${ }^{\mathrm{c}} \mathrm{P}<0.05$ vs. group III; ${ }^{\mathrm{d}} \mathrm{P}<0.05$ vs. group IV; ${ }^{\mathrm{e}} \mathrm{P}<0.05$ vs. group $\mathrm{V}$ 
Table (2): Effect of PPIs, vitamin E, and their combination on hemodynamic parameters on ISO induced MI in rats in different experimental groups

\begin{tabular}{llllll}
\hline & Group I & Group II & Group III & Group IV & Group V \\
\hline $\begin{array}{l}\text { Systolic } \\
\text { BP(mmHg) }\end{array}$ & $117.75 \pm 5.12$ & $97.67 \pm 1.91^{\mathrm{a}}$ & $134.88 \pm 10.67^{\mathrm{a}, \mathrm{b}}$ & $125.88 \pm 6.42^{\mathrm{a}, \mathrm{b}, \mathrm{c}}$ & $112.88 \pm 4.05^{\mathrm{b}, \mathrm{c}, \mathrm{d}}$ \\
$\mathbf{H R}(\mathbf{b} / \mathbf{m})$ & $415.13 \pm 3.40$ & $545.1 \pm 3.48^{\mathrm{a}}$ & $471.88 \pm 8.11^{\mathrm{a}, \mathrm{b}}$ & $456.63 \pm 9.35^{\mathrm{a}, \mathrm{b}, \mathrm{c}}$ & $418.75 \pm 3.33^{\mathrm{b}, \mathrm{c}, \mathrm{d}}$ \\
\hline
\end{tabular}

${ }^{\mathrm{a}} \mathrm{p}<0.05$ vs. control group; ${ }^{\mathrm{b}} \mathrm{p}<0.05$ vs. group II; ${ }^{\mathrm{c}} \mathrm{p}<0.05$ vs. group III; ${ }^{\mathrm{d}} \mathrm{p}<0.05 v s$. group IV; ${ }^{\mathrm{e}} \mathrm{p}<0.05$ vs. group V.

Table (3): Effect of PPIs, vitamin E, and their combination on biochemical changes on ISO induced MI in rats in different experimental groups.

\begin{tabular}{|c|c|c|c|c|c|}
\hline & Group I & Group II & Group III & Group IV & Group V \\
\hline $\begin{array}{l}\text { LDH } \\
(\mathbf{U} / \mathbf{L})\end{array}$ & $166.63 \pm 55.25$ & $1224.38 \pm 109.62^{\mathrm{a}}$ & $529.75 \pm 52.18^{\mathrm{a}, \mathrm{b}}$ & $471.25 \pm 73.33^{\mathrm{a}, \mathrm{b}}$ & $223.63 \pm 36.97^{b, c, d}$ \\
\hline $\begin{array}{l}\text { S.SOD } \\
(\mathrm{U} / \mathrm{ml})\end{array}$ & $12.63 \pm 3.25$ & $3.75 \pm 1.60^{\mathrm{a}}$ & $14.25 \pm 3.20^{\mathrm{b}}$ & $20.5 \pm 1.85^{\mathrm{a}, \mathrm{b}, \mathrm{c}}$ & $29.75 \pm 3.69^{\mathrm{a}, \mathrm{b}, \mathrm{c}, \mathrm{d}}$ \\
\hline $\begin{array}{l}\text { S.MAD } \\
(\mathrm{U} / \mathrm{ml})\end{array}$ & $1.61 \pm 0.29$ & $7.72 \pm 0.52^{\mathrm{a}}$ & $2.02 \pm 0.08^{\mathrm{a}, \mathrm{b}}$ & $1.96 \pm 0.09^{\mathrm{a}, \mathrm{b}}$ & $1.12 \pm 0.19^{\mathrm{a}, \mathrm{b}, \mathrm{c}, \mathrm{d}}$ \\
\hline $\begin{array}{l}\text { NO } \\
(\mu \mathrm{mol} / \mathrm{L})\end{array}$ & $3.59 \pm 0.30$ & $8.44 \pm 0.55^{\mathrm{a}}$ & $4.77 \pm 0.55^{\mathrm{a}, \mathrm{b}}$ & $4.4 \pm 0.72^{\mathrm{a}, \mathrm{b}}$ & $3.65 \pm 0.31^{\mathrm{b}, \mathrm{c}, \mathrm{d}}$ \\
\hline
\end{tabular}

Data are represented as Mean $\pm \mathrm{SD} . \mathrm{P}<0.05$ is considered statistically significant

${ }^{\mathrm{a}} \mathrm{p}<0.05$ vs. control group; ${ }^{\mathrm{b}} \mathrm{p}<0.05$ vs. group II; ${ }^{\mathrm{c}} \mathrm{p}<0.05$ vs. group III; ${ }^{\mathrm{d}} \mathrm{p}<0.05$ vs. group IV; ${ }^{\mathrm{e}} \mathrm{p}<0.05$ vs. group V.

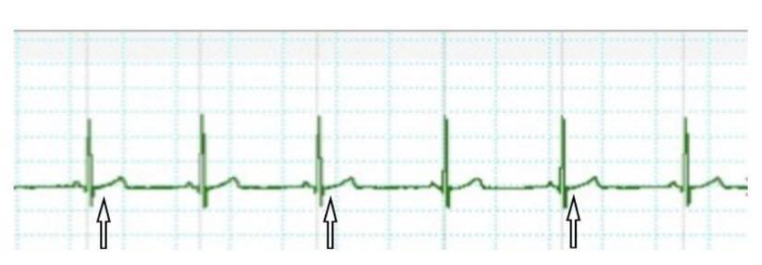

Fig. (1A): Lead II ECG in group I

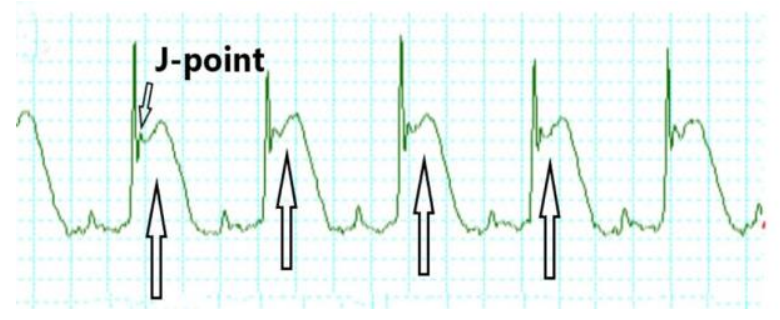

Fig. (1B1): Lead II ECG in group II

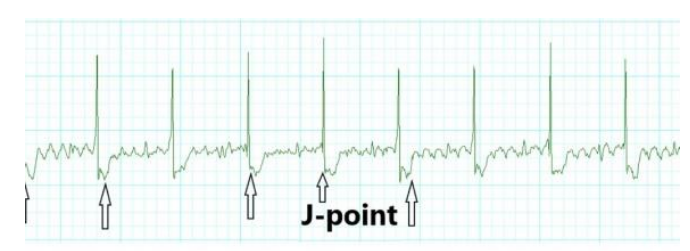

Fig. (1B2): ECG in group II

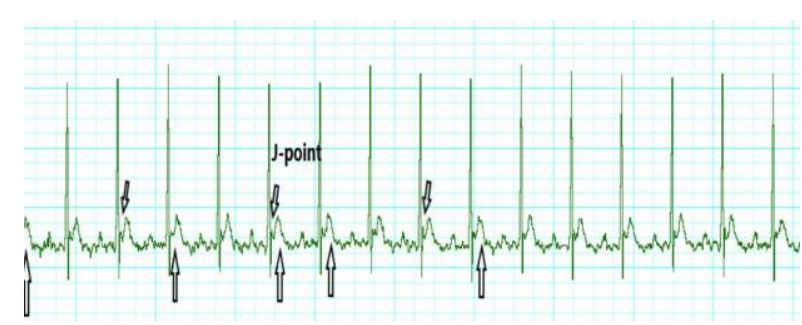

Fig.(1 C): Lead II ECG in

DOI: 10.21608/bmfj.2020.20487.1182 


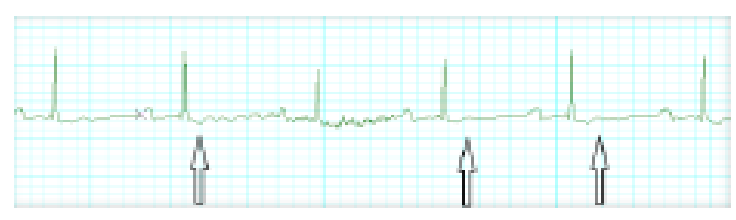

\section{Fig.(1 D): ECG in group V}

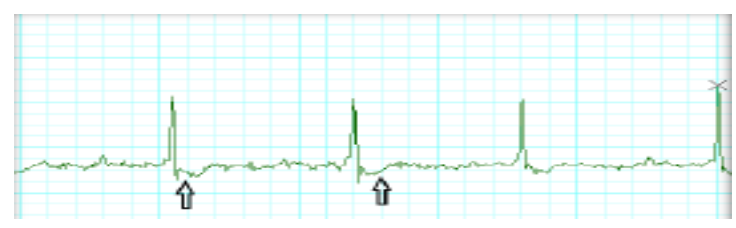

Fig. (1E): ECG in group IV

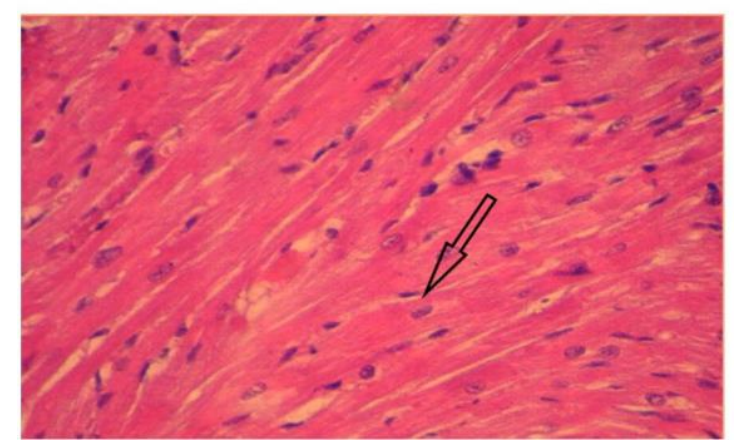

Fig.2 (A) a photomicrograph of section in the cardiac muscle of control group showing normal myocardial muscle striations. Each cardiac muscle fiber has a single oval centrally located nucleus and acidophilic sarcoplasm. They are separated by narrow intercellular spaces. (H\&E X 200).

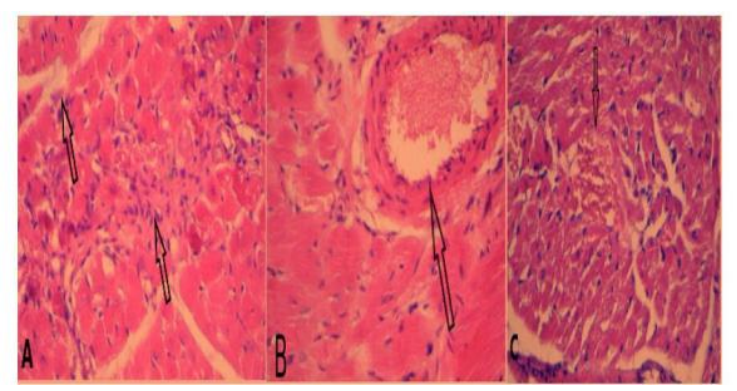

Fig. 2 (B) a photomicrograph of a section in the cardiac muscle of group II showing the following;

A. cardiac muscle fibers are degenerated and separated from each other with wide intercellular spaces. Massive cellular infiltration in between the cardiac muscle fibers. B. dilated and congested blood vessel in between the cardiac muscle fibers. C. sever hemorrhage in between the cardiac muscle fibers (H\&E X 200)

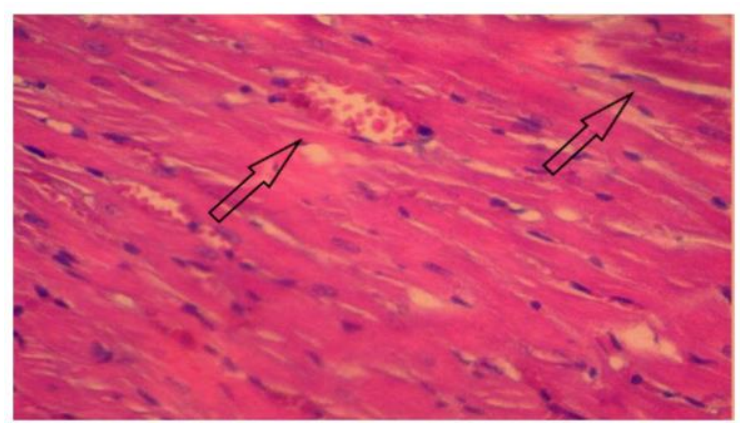

Fig.2 (C) A photomicrograph of a section in the cardiac muscle of group III showing slight hemorrhage in between the cardiac muscle fibers, nearly normal narrow intercellular spaces and less congestion in the cardiac blood vessels (H\&E X 200).

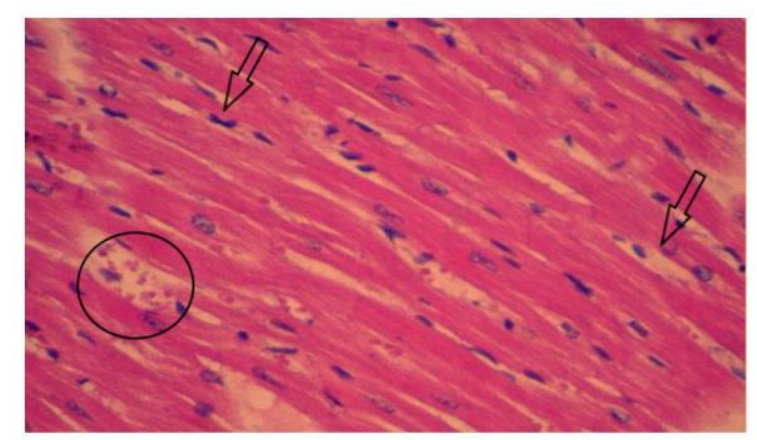

Fig. 2 (D) a photomicrograph of a section in the cardiac muscle of group IV showing that some of the cardiac muscle fibers are interrupted, with little infiltration and minimal widening intercellular spaces (H\&E X 200).

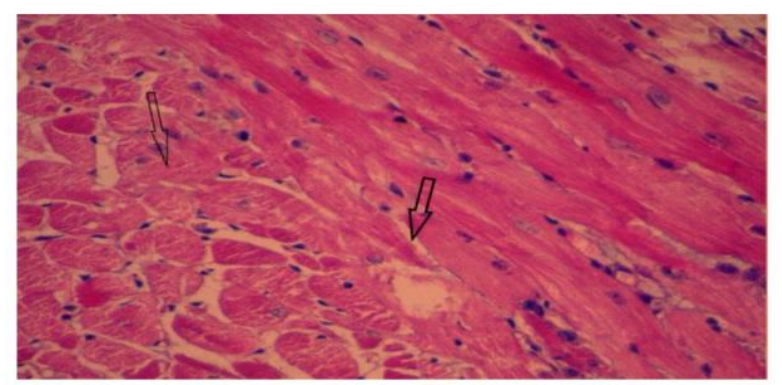

Fig. 2 (D) a photomicrograph of a section in the cardiac muscle of group IV showing that some of the cardiac muscle fibers are interrupted, with little infiltration and minimal widening intercellular spaces (H\&E X 200). 


\section{Discussion}

MI continues to be a major health problem worldwide and contributes significantly to mortality statistics (14). In the current study, infarct-like lesion was induced in rats by intraperitoneal injection of ISO. The purpose of this study was to evaluate the potential cardioprotective role of PPIs and vitamin $\mathrm{E}$ in ISO induced MI in rat model. This was performed with reference to electrocardiographic, biochemical and histopathological changes.

In the present study, S.C. injection of ISO in a dose of $100 \mathrm{mg} / \mathrm{kg} . /$ day for 2 days in group II resulted in myocardial infarction manifested by significant increase in ST segment height and hyperacute $\mathrm{T}-$ wave voltage when compared with control group as shown in table (1), chart (1) and fig. (1) also significant decrease in systolic BP with a significant increase in HR as shown in Table (2). This result agreed with Goyal and his colleagues 2015 mentioned that ISO administration caused a remarkably high ischemic changes in the heart (15)

ISO administration in rats showed a decrease in R-R interval, elevated 'ST-segment' and a depressed 'R-amplitude'. The ST-segment elevation reflects the potential difference in the boundary between the ischemic and nonischemic zones and the consequent loss of cell membrane function. Whereas the decreased R-amplitude might be due to the onset of myocardial edema following isoproterenol administration (16).

Our data revealed the hypotension effect of ISO which came in line with Králové and his colleagues 2008 who reported that isoprenaline injection lead to a massive decrease of peripheral resistance and vasodilatation and to diastolic and systolic pressure decrease, despite positive inotropic and chronotropic effect on the heart (17)

Moreover, our study showed a significant ST segment depression with inverted $\mathrm{T}$-wave as shown in Fig.1(B2) when compared with control group. Jolly and his colleagues 2017 mentioned that ST elevation during acute STEMI is associated with simultaneous ST depression in the electrically opposite leads and this change may point to ischemia in that area (18)

Furthermore, our study indicated that ISO induced MI was associated with a significant increase in serum LDH as shown in Table (3) (19).

Upaganlawar and his colleagues 2009, explained the increase in serum LDH in ISO administration due to increase in oxygen demand of the heart caused by ISO resulting in prolonged ischemia and glucose deprivation. The cells are damaged with 
increased muscle contractility, which results in increasing the cell membranes permeability allowing cardiac enzymes to leak out into the bloodstream (20)

Moreover, our result in the present study revealed that ISO administration in group II resulted in statistically significant increase in serum MDA and serum NO with statistically significant decrease in serum SOD when compared with control group as seen in Table (3) These findings were in line with Riha and his colleagues 2014 (21)

Zaafan and his colleagues 2012 reported that the increase of serum MDA (an indicator of lipid peroxidation) was because of ISO damages antioxidant protective mechanisms, so, rendered the myocardium more vulnerable to lipid peroxidation (22).

The elevation in serum NO could be explained by Ribeiro and his colleagues 2009, as NO is widely recognized as a mediator of vasodilatation with important antiinflammatory and anti-thrombotic properties., who reported that ISO was demonstrated to increase iNOS expression in rats (23).

Moreover, these results were confirmed by histopathological examination of heart tissue, as ISO administered by rats revealed, infiltration of inflammatory cells along with myocyte degeneration as shown in picture (2). These results were in accordance with the previous study of Vennila, L., and Pugalendi, K. V. 2010 (24). These observations along with biochemical and ECG changes confirm the severity of myocardial injury.

In the present work, 3 weeks pretreatment with pantoprazole before ISO injection resulted in significant cardio protection reflected by statistically significant decrease in ST segment height and $\mathrm{T}$ - wave voltage when compared with group II as shown in table (1) and fig. (1). These observations were confirmed by histopathological examination that showed little infiltration and less congestion in the cardiac blood vessels as shown in Pic (3). Our results were in agreement with Schillinger etal.,2007 and Gomes etal.,2011 (25,6).

The improvement in ECG pattern and histopathology picture could be explained by Bacaksiz and his colleagues 2013 who reported that inhibition of the $\mathrm{H}+/ \mathrm{K}+-\mathrm{ATPase}$ pump in myocytes by pantoprazole lead to decrease extracellular $\mathrm{H}+$ transport. So, providing these hydrogen ions for ATP production which is essential in the Nat/ATP-ase exchange pump and consequently prevent accumulation of intracellular sodium and prevent or decrease calcium overload and hyper contracture which are the main causes of ST segment elevation and the hyperacute $\mathrm{t}$ - wave in isoprenaline injected rats (26). 
In addition, Schillinger and his colleagues 2007 informed that pantoprazole decreases hyper contracture in the cardiac muscle which is considered a result from isoprenaline ischemic cascade. It occurred by reduced $\mathrm{Ca} 2+$ influx via L-type calcium channel and reduced $\mathrm{Ca} 2+$ responsiveness of the myofilaments which in turn improve ECG pattern in group III compared with group II (25).

Furthermore, significant decrease in HR with a significant in SBP was observed in group III when compared with group II as shown in Table (2) which came in line with Yenişehirli, A., and Naseri, E. 2008 (27).

Our results also demonstrated a significant decrease in serum LDH and serum NO in group III when compared with group II as shown in Table (3). This result agreed with Abdel-kawy 2015 who reported that pantoprazole seems to preserve the structural, functional integrity and permeability of the cardiac membrane and thus restricting the leakage of LDH enzymes from the myocardium (5).

Also, Nakagawa and his colleagues 2012 came in harmony with our result suggested that PPIs inhibited NO production by suppressing NADPH oxidase activity and thus decrease lipid peroxidation (28).
Our data also showed a significant decrease in serum MDA with a significant increase in serum SOD in group III when compared with group II as shown in Table (3). This result revealed pantoprazole anti-oxidant and cytoprotective effects which came in line with Jeremic and his colleagues 2018 who demonstrated that proton pump inhibitors having the sulphoxide group are able to scavenge hydroxyl radicals and protects the cardiac cell through destruction of cell damaging ROS by suppressing NADPH oxidase activity (29).

In our research, pretreatment with vitamin $\mathrm{E}$ in dose for 3 weeks resulted in significant cardio protection showed by statistically significant in ST segment height, $\mathrm{T}$ - wave voltage and $\mathrm{HR}$ with a significant increase in SBP when compared with group II, moreover there was significant decrease in SBP and HR when compared with group III as shown in Table (1and2) and fig.1, when compared with group II. These findings were confirmed by histopathological studies as shown in Pic.4 which revealed minimal edema and little widening intercellular spaces. So, vitamin E showed its effect in preserving the integrity of heart tissues. Our results were in agreement with Upaganlawar and his colleagues 2009, reported the cardioprotective effect of vitamin E (20). 
In addition, Blum and his colleagues 2010 demonstrated that nutritionally supplemented $\alpha$-tocopherol can reduce myocardial ischemia reperfusion injury as evidenced by its ability to improve ventricular function and reduce infarct size and cardiomyocyte apoptosis (30).

In current work, there was a significant decrease in serum LDH, serum NO and serum MDA with significant increase in serum SOD in group IV when compared with group II, also there was a significant increase in serum SOD when compared with group III as shown in Table (3) these findings reflected vitamin $\mathrm{E}$ antioxidants and anti-inflammatory activity and these were in accordance with Radovanovic and his colleagues 2012 (31)

Huwait and Al-Ghamdi 2017 came in line with our findings, as they demonstrated that the ability of vitamin E to scavenge lipid radicals and terminate oxidative chain reactions. It can terminate radical chain reactions by interacting with the lipid peroxyl radical, preventing it from generating a new radical and preserving the chain reaction by oxidizing other lipids (32).

Noteworthy, there were non-significant changes ( $\mathrm{p}$-value $>0.05$ ) in the assessed parameters between pantoprazole and vitamin E that means vitamin E supplementation may be a substitution for condition of contraindicated PPIs administration.
Finally, our study revealed that with comparison to ISO infarcted group II, when vitamin $\mathrm{E}$ was supplemented along with pantoprazole administration after induction of experimental MI by ISO resulted in a significant decrease in ST segment height and $\mathrm{T}$-wave voltage (table 1,fig.1), also in serum LDH, MDA,NO (table 3) in addition to HR (table 2), while there was a significant increase in SBP (table 2) and in serum SOD (table 3). In addition, histopathological studies, confirmed these findings as it showed that the cardiac tissue appeared nearly normal histological structure with narrow intercellular spaces and minimal hemorrhage. This might be explained by a synergistic effect that could be exerted by both pantoprazole and vitamin $\mathrm{E}$ on hemodynamic parameters preservation and antioxidant mechanisms.

From our study we can conclude that three weeks pretreatment with either pantoprazole or Vitamin E can exert a cardio-protective effect against ISO induced infarction. as they reverse the effects of MI by reducing the extent of myocardial damage, via reduction of intracellular calcium overload, maintenance of endogenous antioxidants status and attenuating the oxidative stress, with more beneficial effect of their combination approach with targeting to restore myocardium integrity. 


\section{Reference}

1. Thygesen, K., Alpert, J. S., Jaffe, A. S., Chaitman, B. R., Bax, J. J., Morrow, D. A., et al. (2018). Fourth universal definition of myocardial infarction (2018). Journal of the American College of Cardiology, 72(18), 2231-2264.

2. Hamssika, C., Sakeena, Q., Ramakrishnan, G., Sugumar, M., Sathyanarayana, B., Shetty, M. V., et al (2018). Protective role of heartogen against myocardial infarction in rats. International Journal of Nutrition, Pharmacology, Neurological Diseases, $8(3), 92$.

3. Siddiqui, B. S., Ali, S. T., Tauseef, S., Kamal, S., Rizwani, G. H., Begum, S., et al (2016). Isoprenaline a tool for inducing myocardial infarction in experimental animals. Int $\mathbf{J}$ Pharm 2016; 6(2): 138-144

4. Shin JM, Sachs G (2008). Pharmacology of proton pump inhibitors. Curr Gastroenterol Rep.;10(6):528-34.

5. Abdel-kawy, H. S. (2015). Chronic Pantoprazole Administration and Ischemia-Reperfusion Arrhythmias In Vivo in Rats-Antiarrhythmic or Arrhythmogenic? Cardiovascular therapeutics, 33(2), 27-34.

6. Gomes, O. M., Magalhães, M. D. M., Abrantes, R. D., and Kallás, E. (2011). Pantoprazole provides myocardial protection similar to ischemic preconditioning: experimental study of isolated hearts of rats. Brazilian Journal of Cardiovascular Surgery, 26(3), 433-439..

7. Traber, Maret G., and Jan F. Stevens (2011). "Vitamins C and E: beneficial effects from a mechanistic perspective." Free Radical Biology and Medicine 51.5: 1000-1013.
8. Cooper, H. A., Rao, S. V., Greenberg, M. D., Rumsey, M. P., McKenzie, M., Alcorn, et al. (2011). Conservative versus liberal red cell transfusion in acute myocardial infarction (the CRIT Randomized Pilot Study). The American journal of cardiology, 108(8), 1108-1111.

9. Kumaran, K. S., and Prince, P. S. M. (2010) Caffeic acid protects rat heart mitochondria against isoproterenol-induced oxidative damage. Cell stress and chaperones, 15(6), 791-806.

10. Iwamoto, K.; Chein, C. and Kato L. (1987): Effect of urethane anesthesia and age on organ blood flow in rats measured by hydrogen gas clearance method. J. Pharmacobiodyn.; 10(6): 280 - 4 .

11. Green, L. C., Wagner, D. A., Glogowski, J., Skipper, P. L., Wishnok, J. S., and Tannenbaum, S. R. (1982). Analysis of nitrate, nitrite, and [15N] nitrate in biological fluids. Analytical biochemistry, 126(1), 131-138.

12. Draper, H. H., and Hadley, M. (1990). Malondialdehyde determination as index of lipid Peroxidation. In Methods in enzymology (Vol. 186, pp. 421-431). Academic press.

13. Nishikimi, M., Rao, N. A., and Yagi, K. (1972). The occurrence of superoxide anion in the reaction of reduced phenazine methosulfate and molecular oxygen. Biochemical and biophysical research communications, 46(2), 849-854.

14. Patel, M. R., Mahaffey, K. W., Garg, J., Pan, G., Singer, D. E., Hacke, W., et al., (2011). Rivaroxaban versus warfarin in nonvalvular atrial fibrillation. New England Journal of Medicine, 365(10), 883-891.

15. Goyal, S. N., Sharma, C., Mahajan, U. B., Patil, C. R., Agrawal, Y. O., Kumari, S., et al., (2015). Protective effects of cardamom in isoproterenol- 
induced myocardial infarction in rats. International journal of molecular sciences, 16(11), 2745727469.

16. Forechi, L., Baldo, M. P., Meyerfreund, D., and Mill, J. G. (2012). Granulocyte colony-stimulating factor improves early remodeling in isoproterenolinduced cardiac injury in rats. Pharmacological Reports, 64(3), 643-649.

17. Králová, E., Mokran, T., Murin, J., and Stankovicova, T. (2008). Electrocardiography in two models of isoproterenol-induced left ventricular remodeling. Physiol Res, 57(Suppl 2), S83-9.

18. Jolly, S. S., James, S., Džavík, V., Cairns, J. A., Mahmoud, K. D., Zijlstra, F., et al.,. (2017). Thrombus aspiration in ST-segment-elevation myocardial infarction: an individual patient metaanalysis: Thrombectomy Trialists Collaboration. Circulation, 135(2), 143-152.

19. Moradi-Arzeloo, M., Farshid, A. A., Tamaddonfard, E., and Asri-Rezaei, S. (2016). Effects of histidine and vitamin $\mathrm{C}$ on isoproterenolinduced acute myocardial infarction in rats. In Veterinary Research Forum (Vol. 7, No. 1, p. 47). Faculty of Veterinary Medicine, Urmia University, Urmia, Iran.

20. Upaganlawar, A., Gandhi, C., and Balaraman, R. (2009). Effect of green tea and vitamin E combination in isoproterenol induced myocardial infarction in rats. Plant foods for human nutrition, 64(1), 75-80.

21. Říha, M., Vopršalová, M., Pilařová, V., Semecký, V., Holečková, M., Vávrová, J., et al., (2014). Oral administration of quercetin is unable to protect against isoproterenol cardiotoxicity. NaunynSchmiedeberg's archives of pharmacology, 387(9), 823-835
22.Zaafan, M. A., Zaki, H. F., El-Brairy, A. I., and Kenawy, S. A. (2012). Isoprenaline-induced myocardial infarction in rats: protective effects of hesperidin. Egyptian Journal of Basic and Clinical Pharmacology, 2(2), 13-22.

23. Ribeiro, D. A., Buttros, J. B., Oshima, C. T., Bergamaschi, C. T., and Campos, R. R. (2009). Ascorbic acid prevents acute myocardial infarction induced by isoproterenol in rats: role of inducible nitric oxide synthase production. Journal of molecular histology, 40(2), 99-105.

24. Vennila, L., and Pugalendi, K. V. (2010). Protective effect of sesamol against myocardial infarction caused by isoproterenol in Wistar rats. Redox Report, 15(1), 36-42.

25. Schillinger, W., Teucher, N., Sossalla, S., Kettlewell, S., Werner, C., Raddatz, D., et al., (2007). Negative inotropy of the gastric proton pump inhibitor pantoprazole in myocardium from humans and rabbits: evaluation of mechanisms. Circulation, 116(1), 57-66.

26. Bacaksiz, A., Teker, M. E., Buyukpinarbasili, N., Inan, O., Tasal, A., Sonmez, O., et al., (2013). Does pantoprazole protect against reperfusion injury following myocardial ischemia in rats. Eur Rev Med Pharmacol Sci, 17(2), 269-75.

27. Yenişehirli, A., and Naseri, E. (2008). Omeprazole, lansoprazole and pantoprazole had no effect on blood pressure and electrocardiogram of anesthetized rat. Pharmacological research, 58(1), $65-71$.

28. Nakagawa, S., Arai, Y., Kishida, T., Hiraoka, N., Tsuchida, S., Inoue, H., et al., (2012). Lansoprazole inhibits nitric oxide and prostaglandin E 2 production in murine macrophage RAW 264.7 cells. Inflammation, 35(3), 1062-1068. 
29. Jeremic, N., Zivkovic, V., Srejovic, I., Jeremic, J., Petkovic, A., Bradic, J., et al., (2018). effects of ischeMic and Proton PuMP inhiBitors PreconditioninG on oXidatiVe stress of isolated rat heart. Serbian Journal of Experimental and Clinical Research.

30. Blum, S., Vardi, M., Levy, N. S., Miller-Lotan, R., and Levy, A. P. (2010). The effect of vitamin E supplementation on cardiovascular risk in diabetic individuals with different haptoglobin phenotypes. Atherosclerosis, 211(1), 25.

31. Radovanovic, S., Savic-Radojevic, A., PljesaErcegovac, M., Djukic, T., Suvakov, S., Krotin, M., et al., (2012). Markers of oxidative damage and antioxidant enzyme activities as predictors of morbidity and mortality in patients with chronic heart failure. Journal of cardiac failure, 18(6), 493501.

32. Huwait, E. A., and Al-Ghamdi, M. A. (2017). Protective role of carnitine synergized with vitamin $\mathrm{E}$ against isoproterenol induced cardiac infarction in rats. African Journal of Traditional, Complementary and Alternative Medicines, 14(2), $25-32$.

To cite this article: Abeer A. Shoman, Effect of Proton Pump Inhibitors, Vitamin E and their co- administration on heart function and Oxidative Changes in Isoprenaline Induced Myocardial Infarction in Adult Male Albino Rats. BMFJ. 2019;37(1):169-183, DOI: 10.21608/bmfj.2020.20487.1182 